\title{
Cascas de baNaNa NO Caminho do TRADUTOR
}

\author{
Paulo Rónai \\ Conferência proferida no Departamento \\ de Letras da U.F.Pr.
}

Prosper Mérimée, grande contista francês, autor, entre outras obras de valor clássico, de Carmen e de Colomba, era também tradutor de mérito excepcional. Foi ele quem divulgou primeiro na França os autores russos e é, portanto, responsável pela expansão de suas obras em todo o Ocidente. Homem espirituoso e irônico, tinha adotado como lema de sua vida particular o adágio grego "Lembra-te de desconfiar". Podemos pedir-lhe emprestado esse ditado para divisa do tradutor, já que a qualidade mais importante exigido por seu oficio é uma desconfiança perpétua.

Pois esse profissional vive percorrendo caminhos ingremes, ladeados de abismos e semeados de cascas de banana. A nossa palestra de hoje será dedicada à identificação de algumas dessas últimas. Na verdade, o número dessas é legiăo, pois, como veremos, não há qualquer palavra, por mais simples que seja, que não possa encerrar, em determinadas circunstâncias, alguma ambiguidade, e, portanto, transformar-se em perigosa armadilha.

Nāo esperem de nós uma teoria da tradução com definiçōes e regras rixas. Ainda que pudessem ser formuladas, pouco lhes ensinariam sobre o processo efetivo da tradução. Se me perguntarem o que é vermelho, poderei citar a medida exata em mikrons do comprimento de onda das radiaçōes que produzem essa cor, e ainda assim não a veriam; mas se lhes disser que é a cor do sangue e do fogo, ou simplesmente thes mostrasse uma papoula, a sua curiosidade estaria satisfeita.

Naturalmente se a pergunta fosse feita por um cego, não haveria como satisfazê-lo. Considero cego em matéria de tradução a pessoa indiferente aos requintes da própria língua, que não procura normalmente a melhor maneira de se exprimir, e fala e escreve ao deus-dará; esta, naturalmente, não se tornará tradutor nem a pau.

Minhas palavras dirigem-se àqueles que cuidam de melhorar o dom da fala que Deus lhes deu, se interessam pelo 
idioma, lêem muito e com atenção. Nestes pretendo inculcar, com a palestra de hoje, coleção de amostras antes de que preceitos, lim medo salutar diante de qualquer texto que lhes caiba verter em português. esse medo que os estimulará a não esmorecerem no estudo mesmo depois de formados, a não pararem de se aperfeiçoar ao longo de toda a sua carreira.

Quem vai falar-lhes é um tradutor literário. Mas os fenômenos que apontarmos interessam da mesma maneira toda espécie de tradutores, pois todos trabalham a mesma matéria-prima, a lingua, misteriosa realidade impalpável que nos circunda por todos os lados.

$$
\text { :: }: \because: \quad \because
$$

Dando por óbvio que o tradutor conheça a fundo a própria lingua, o conhecimento sólido da língua de que ele traduz é outra exigência de que não se pode abrir mão. $\mathbf{E}$ deve ser um conhecimento gramatical e lexical, tão completo quanto possivel.

Em matéria gramatical, o candidato a tradutor deverá trazer na ponta da lingua todas as formas irregulares de conjugação e todas as flexões insólitas da declinação, tanto mais porque elas nem sempre vêm registradas na ordem alfabética dos dicionários. Saberá distinguir as formas arcáicas das modernas, as giriescas das comuns, as faladas das escritas. Terá consciência especialmente aguda dos fenômenos que não existem em sua própria língua.

Se traduzir do francês, deverá conhecer a fundo os ardis dos advérbios pronominais en e y: se do italiano, o manejo difícil dos pronomes átonos fundidos com o verbo, em scrivermela, facendoglisi, fateglielo; se do alemão, a distinção de verbos de prevérbio móvel, como wiedersehen, zusammenkommen, dos de prevérbio fixo, como übersetzen, beschreiben; se do latim, a relação das preposições que pedem acusativo e das que pedem ablativo, e assim por diante. Tudo isso parece natural e escusado de dizer: tantos são, no entanto, os inconscientes que se aventuram a traduzir sem estarem compenetrados das regras de funcionamento gramatical da língua de partida que julgamos necessário lançar essa advertência preliminar.

$$
* * *
$$

Em matéria lexical, a primeira e principal fonte de confusão está em grande parte de as palavras possuírem vários sentidos. Se elas tivessem apenas um único sentido bem determinado - como, p.ex., alfinete, aspirina e centimetro, a 
tradução seria coisa relativamente fácil. Mas a maioria dos vocábulos usados na lingua de todos os dias tem várias acepções, registradas e muitas vezes numeradas nos dicionários, e que podem ser bastante afastadas umas das outras.

A esse fenômeno dá-se o nome de polissemia e ela se verifica em todos os idiomas. Cientes do perigo que ela representa para a clareza do discurso, os criadores de línguas artificiais, entre eles Zamenhof, pai do esperanto, trataram de eliminá-lo, dando a seus vocábulos um sentido único, bem delimitado. Precaução inútil: devido à tendência da mente humana para a extensāo metafórica, logo eles foram assumindo sentidos novos.

Mas, dir-me-ão, se o fenômeno é comum a todas as línguas, não tem por que nos assustar. Mas somente em casos muito raros dois vocábulos correspondentes de duas línguas têm as mesmas acepções, como o fr. punaise e o port. percevejo, que indicam ambas certo inseto e certo tipo de prego.

Mas já o substantivo francês prix, que corresponde a nosso "preço", tem também a acepçāo de "prêmio"; ou outro substantivo, rapport, equivale em português a "relação", mas pode também significar "relatório". Necessitamos de contexto para podermos entendê-los e traduzi-los. Só depois de lermos toda a expressāo le prix Nobel sabemos que se trata de um prêmio, ou depois de ouvirmos falar de rapport Kinsey entendemos que se pensa num relatório.

$O$ contexto às vezes é bem maior que uma única frase ou uma simples expressão. $O$ tradutor que tivesse de verter um romance francês intitulado adresses, teria que ler pelo menos algumas páginas do volume para saber se o intitula "endereços" ou "habilidades".

Esse último exemplo prova que mesmo vocábulos da mesma origem em duas linguas podem ramificar de maneira diferente. $O$ francês maitre tem os principais sentidos do nosso "mestre", mas pode também significar "amo" por oposiçāo a "criado" ou "escravo".

De onde podemos tirar a conclusão que o sentido da palavra não é contido apenas nela própria, mas lhe vem das palavras que a rodeiam. Ótima prova disso está nas duas frases alemās Er dient e Sie dient, das quais a primeira é entendida como "Ele está fazendo o serviço militar" e a segunda como "Ela trabalha como empregada".

A dificuldade que nos causa a polissemia das palavras, francesas, alemães ou inglesas, pagamo-la na mesma moeda quando nacionais desses paises se metem a traduzir nossos livros. Um francês que tivesse um conhecimento apenas superficial do nosso vocabulário, enganar-se-ia facilmente ao enfrentar a palavra papagaio, quando ela designa não a ave multicolor, mas o brinquedo designado também por "pipa" 
ou "pandorga". E mesmo que não ignore esse sentido estará no mato sem cachorro quando se der com uma história em que alguém paga todo um vagão de mercadorias por meio de um único papagaio, isto é, uma letra de câmbio ou promissória.

Uma das causas da polissemia é a tendência do nosso espírito para a metáfora, verificavel em todas as línguas. Ocorre-nos quase naturalmente chamar uma criança de bichinho, uma bela mulher de flor, ou falarmos em pé da montanha, em fundo da questāo, em cabeça de motim. Quando a metáfora de tāo óbvia existe em todas as línguas, ou mesmo quando representa uma nova maneira de ver, peculiar a um autor, traduz-se com a possível fidelidade. A dificuldade começa quando a expressão metafórifa passa a fazer parte estereotipada da língua, transformando-se em locução figurada. Quem as usa em sua língua, nem percebe mais a imagem que lhes deu nascença; mas o tradutor que, por ignorância, as considerasse criaçōes individuais e restabelecesse a imagem, cometeria erro palmar.

Tomemos o vocábulo alemão Handschuh, "luva", composto de Hand e Schuh. Para nenhum alemăo ele evoca a idéia de "sapato"; o brasileiro que o traduzisse assim, cairia no ridículo. O erro não é muito provável, não só por se tratar de termo muito comum, mas porque os dois elementos da palavra sāo fundidos. Já as criaçōes francesas bellemère ("sogra"), belle-fille ("nora"), beau-père ("sogro"), beau-fils ("genro") são responsáveis por inúmeras cincadas, apesar de ligadas por hifen. O caso piora quando as palavras que compōem a expressão nem por hífen estão unidas: assim tête de mort ("caveira") e tête de Turc ("alvo de zombarias").

$O$ terreno preferencial dos enganos são os modismos figurados de certa extensão. $E$ verdade que frequientemente os mesmos fenômenos inspiram expressāo figurada em várias línguas; só que as imagens que lhes servem de base não sāo as mesmas. O nosso "pé-de-boi" torna-se em França un bourreau de travail. Enquanto o brasileiro "faz das tripas coração", o francês prend son couragc à deux mains. Outros exemplos parecidos: ne rimer à rien, "não ter pé nem cabeça"; une soupe au lait, "uma pessoa esquentada", e poser un lapin, "dar um bolo em alguém".

Ocorrem-me no momento, no domínio do inglês, matchmaker, que comumente não designa um "fabricante de fósforos", e sim um "concertador de casamentos"; e sleeping partner, que é o sócio secreto num negócio, que geralmente mantém os olhos bem abertos.

Identificar tais ciladas requer, além de bom senso, muita atenção e bastante experiência. (Uma boa coleção, para o francês, está no Dicionário Francês-Português de Locuções, 
de Aluizio Mendes Campos, Edições Ática. O saudoso Prof. Oswaldo Serpa publicou várias coletâneas de locuções inglesas, uma delas em edição do Ministério da Educação).

$\mathrm{E} \circ$ momento de citar alguns lapsos provindos do não reconhecimento de locuçōes metafóricas". "Golpe de alfinete" seria a traduçāo errada un coup d'épingle, "alfinetada"; pior ainda "quebrar os cachorros", de rompre les chiens, isto é, "interromper a conversa". "Sou uma velha mão nisto" $\dot{e}$ simplesmente $\mathrm{I}$ am an old hand at it, isto é, "tenho muita prática no assunto".

Um dos casos mais curiosos dá-se quando a própria metáfora é usada metaforicamente. Os bons conhecedores lo inglês sabem que a expressão man-of-war (atenção aos dois hifens!) designa um navio de guerra. Sabia-o o colaborador do Jornal do Brasil, que teve de traduzir uma nota sobre uma valente nadadora, disposta a chegar a nado de Cuba aos Estados-Unidos; mas não sabia que a expressão Portuguese man-of-war era outra metáfora para designar o bicho marinho, conhecido entre nós como medusa ou água-viva. E assim foi escrever galhardamente que a desportista encontraria sérias dificuldades, por serem aquelas águas infestadas de navios de guerra portugueses, sem perceber o absurdo contido em semelhante afirmaçāo. Eis um caso onde um pouco de bom senso the teria aconselhado uma consulta ao dicionário.

Das palavras polissêmicas distinguem-se os homônimos, pares de palavras de aparência igual, mas de sentido diferente, que são também causadores de múltiplos enganos. Sem dúvida, temo-los em nossa própria língua, mas ai nós nos livramos de seus perigos graças ao contexto em que aparecem. Se o nosso convidado nos disser durante o almoço que logo depois vai fazer a sesta, logo entenderemos, salvo o caso pouco provável de ele ser cesteiro de profissão, que ele deseja tirar uma soneca e nāo fabricar um balaio. Na língua estrangeira, porém, podemos embaralhar-nos ou por só conhecedmos um dos dois homônimos, ou por não entendermos o contexto.

Quando se trata apenas de homófonos, palavras do mesmo som, mas de grafia diferente, 0 aspeto adverte-nos: sceau ("selo"), seau ("balde") e sot sāo reconhecíveis e distinguíveis graças à escrita. Mas em se tratando de homógrafos, palavras de forma igual, o erro torna-se bem mais fácil. Para quem não conhece a palavra francesa nue, sinônimo mais raro de nuage, a expressão tomber des nues constituirá um enigma, pois para ele aquelas letras indicam apenas "nua". Dá-se o mesmo com a palavra mine. Quem só conhece 
como equivalente de nossa "mina", não entenderá quando o cumprimentarem pela sua boa aparência: Vous avez bonne mine. Surpresas iguais terá o "tradutor" de inglês que não souber distinguir pole ("polo") de pole ("vara", "poste") ou pool ("poçad'água" de pool ("combinação de cartas de jogar").

Citemos mais alguns pares de homônimos responsáveis de grande número de confusōes: em francês, feu "fogo" e "falecido"; em inglês, light, "leve" e "luz"; em castelhano, pez, "peixe" quando masculino, "piche" quando feminino: em italiano, vita "vida" e "cintura"; em alemão, Weise, "sábio" e "maneira"; em latim, latus, "lado" e "largo". Na verdade, em cada uma dessas línguas poder-se-iam arrolar dúzias desses pares de vocábulos capciosos.

Mas esse número é ampliado ao infinito pela desatenção ou pela ignorância dos tradutores. Erwin Theodor cita 0 caso de um tradutor de alemão que, despercebido do trema do segundo destes vocábulos, confundiu schon e schön; Dom Marcos Barbosa lembra o especialista de francês que traduziu la pucelle d'Orléans por "a pulga de Orleães", tomanđo pucelle por puce; Magalhães $\mathrm{Jr}$. cita o colega de inglês, que tomou General Staff por um oficial superior; e eu mesmo já encontrei j'ai attrapé un rhume terrible traduzido por "tomei um copo de rum horrivel", devido à confusão entre rhum ("rum") e rhume ("resfriado").

$$
\text { * } * * *
$$

Entre os elementos de língua suscetiveis de dar confusão precisa-se mencionar ainda os parônimos, palavras quase homônimas de tão parecidas: assim em francês émigrant e immigrant, ou émigrant e émigré, ou ainda rabattre e rebattre, ou então repartir e répartir. Conceberemos como é fácil confundir tais pares de vocábulos se nos lembrarmos quão freqüentemente em português os parônimos vêm a ser trocados, pois quando não os autores, os tipógrafos teimam em tomar apreender por aprender, usuário por usurário, estático por estético e lúdico por lúcido.

$$
\text { * } * *
$$

Poderia alguém pensar que os sinônimos, pelo menos, não constituem um problema, antes uma ajuda para o tradutor. Parece lógico, de fato, nos casos em que não encontramos equivalente satisfatório para um termo, procurar o equivalente de um de seus sinônimos. Não havendo equivalente, em português, para marron, lançamos mão do equivalente de châtaigne, "castanha". 
Entretanto os sinônimos, ainda que nāo apresentem diferença percebivel de sentido, geralmente correspondem a niveis de lingua diferentes, daí nem sempre serem trocáveis. De debut e commencement, o primeiro pertence mais ao uso literário, o segundo ao uso oral; de j'ai entendu dire e j'ai oui dire, o primeiro é mais moderno que o segundo. Nas locuções, então, os sinônimos não se substituem mesmo; em França, on rompt des fiançailles, on casse un jugement, on brise une carrière - como, aliás, em português, "rompe-se" com a namorada" e "quebra-se a cara" do desafeto. Para dar outro exemplo ainda mais convincente, citarei o nosso vocábulo "progenitora", sinônimo de "mãe" mas que na maioria dos casos não o pode substituir sem suscitar um sorriso. Pascal dizia que havia trechos onde era preciso dizer Paris e outros onde convinha dizer capitale du rovaume, observação tão importante para o tradutor como para o escritor. A questão dos sinônimos é, na verdade, uma questão de estilo; bem o sentia Jules Renard ao escrever: "Não há sinônimos; existem apenas as palavras necessárias e o bom escritor as conhece".

$$
\div \quad * \quad *
$$

Inimigos bem mais piores para o tradutor são os chamados "falsos-amigos" ou deceptive cognates, isto é, palavras de forma igual em duas línguas, mas de sentido diferente. Freqüentemente são vocábulos da mesma origem, que, no decorrer da evolução, assumiram significados diferentes. Assim o fr. jument nāo é nem "jumento", nem "jumenta", mas "égua"; mater não é "matar", apenas "dar mate" no jogo de xadrez; remarquer não é "remarcar", mas "observar" ou "notar".

Mais de uma vez, porém, a semelhança é mera coincidência: de origens diferentes, foram aproximados pela evolução fonética e ortográfica das respectivas línguas: o francês fiel ("fel") nada tem que ver com o nosso "fiel", nem cor ("calo") com o nosso "cor".

Piores são os falsos-amigos que nem sempre são falsos: isto é, que se equivalem em certas acepçōes, mas noutras não. Exemplo disto é o inglês intelligence, que corresponde a nossa "inteligência" no sentido de "intelecto", mas nāo no de "informação"; ou devout, que às vezes pode ser "devoto", mas outras vezes é "entusiasmado".

Todo tradutor lembrará, dentro de sua praxe, algum exemplo divertido dos estragos dos falsos-amigos. Magalhães Jr. conta de um "tradutor" que verteu éleveur de moutons ("criador de carneiros") por "elevador de carneiros". Julio Cortazar recorda este achado de um "profissional hispano- 
americano: "la vaca no habla" como versāo de res non verba ("coisas, não palavras". Citarei, afinal, uma pérola encontrada numa coleção norte-americana de boners (besteiras recolhidas em cadernos ou na boca de alunos), pérola bonita demais para ser verdadeira: le peuple ému répondit $=$ the purple emu laid another egg.

Para beneficio do tradutor de francês, arrolei os deceptive cognates dessa língua em meu Guia Prático da Tradução Francesa; Agenor Soares Santos fez o mesmo para o inglês em Guia Prático da Tradução Inglesa; ambos os livros têm ampla exemplificaçāo. Coletâneas semelhantes não existem, mas seriam bem necessárias, para o italiano e o castelhano; uma pequena relação de falsos-amigos de ambos encontra-se em A Arte de Traduzir, de Breno Silveira, infelizmente esgotada. Quem trabalhar com um desses dois idiomas, fará bem em anotá-los ao acaso de suas leituras e trabalhos.

A fim de dar uma idéia das gafes em que o tradutor de italiano pode incorrer, citarei sete, que não é "sete", mas "sede"; presunto que é "presumido"; paio que é "ar"; oca que é "ganso"; dito, que é "dedo", e calza, que é "meia".

Chama-se interlegibilidade a possibilidade de se ler uma língua que não se fala, de que, por exemplo, nós brasileiros nos beneficiamos em relação ao castelhano. E, ao mesmo tempo, uma facilidade e um perigo. A semelhança das duas linguas leva-nos frequentemente a adivinhar em vez de interpretar: se fôssemos ao dicionário, saberíamos que criança significa criação ou educação, polvo é "pó" e ratito um "momentinho". Mesmo quando entre palavras de formas iguais não há esses abismos de sentido, o uso corrente das duas pode diferir bastante: e é por isso que muitas vezes entendemos menos a tradução portuguesa de um livro espanhol do que o proprio original.

Esse inferno, naturalmente, está aberto aos nossos colegas hispanófonos tanto quanto a nós. Fala Julio Cortazar de um estudante espanhol que conseguiu traduzir com muita rapidez um contrato italiano para a sua lingua, sem saber explicar, porém, porque nele tanto se falava em "papagaio" (loro).

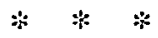

Nesta resenha rápida, bem entendido, é impossível passar revista a toda a espécie de alçapões que o tradutor encontra em sua atividade profissional. Mesmo assim, não poderiamos deixar de lado os riscos originários da diferença do fundo cultural. Toda lingua é um arquivo de reminiscências históricas, de alusões e acontecimentos e personagens de um pasado comum, cujo conhecimento é indispensável a quem se mete a tradutor. Estou pensando em migalhas de civiliza- 
ção como entre nós, o "fico", o famoso grito de Ipiranga. Quando se diz em Portugal "Ines é morta", pode o falante nem se lembrar mais do evento histórico em que se originou o ditado; o italiano que disser, quase no mesmo sentido, "Non é piú il tempo che Berta filava", pode até ignorar a identidade de Berta, mas entenderá perfeitamente a exclamaçāo saudosa. Todos os franceses conhecem a frase atribuida a MariaAntonieta: 'S'ils n'ont pas de pain, qu'ils mangent de la brioche".

Quando se diz em hüngaro "Falta ainda a sopa preta", os falantes dessa lingua entendem que o pior está para vir. Descobriu-se que tal frase fora pronunciada pela primeira vez no fim de um jantar a que o sultāo da Turquia convidou alguns fidalgos húngaros, para anunciar o cafezinho, que ainda não tinha nome em húngaro no século XVI; mas como os hóspedes, logo depois do café, foram presos e encarcerados, a sentença ganhou conotação trágica.

Nem sempre os fragmentos de cultura conservados na linguagem têm esse halo histórico: eles podem ser os simples reflexos de hábitos comuns do dia-a-dia. Existe em Paris um sistema ultra-rápido de comunicação, pelo qual cartas escritas em papel fino são expedidas através de canos de ar comprimido de um bairro para outro. A cartas assim entregues dá-se o nome de lettre pneumatique, popularmente pneu. O tradutor que desconhecesse tal instituição não entenderia porque certa personagem de romance, que nem automóvel possui, ganha de presente um pneumático. Não menor será seu espanto ante o curriculo escolar de um menino que, aprovado, passasse da quinta série para a quarta - já que na França as séries do colégio se sucedem às avessas. Lendo, num conto de autor húngaro, que uma camponesa húngara para sair veste as saias, o tradutor jejuno, julgando que se trata de evidente erro tipográfico corrigirá o plural em singular - por ignorar que é hábito das moças magiares do campo, sobretudo nos dias de festa, vestirem ao mesmo tempo quantas saias têm.

Essas minúcias fazem compreender que traduzir é muito mais do que simplesmente trocar as palavras de uma língua pelas de outra; é estabelecer uma série de contatos entre duas culturas, duas realidades, sem cujo conhecimento intenso a operaçāo tradutora está condenada ao fracasso. Elas mostram também cabalmente que o tradutor não pode ser uma pessoa inculta, de horizontes fechados; tem que ser alguém de curiosidade sempre desperta, já que o desconhecimento do ambiente do original não constitui circunstância atenuante, assim como o desconhecimento da lei não isenta de culpa o contraventor.

$$
* * *
$$


Citaremos agora três campos aparentemente livres de emboscadas: os dos nomes próprios, dos numerais e das siglas. Estes, ao menos, não deveriam trazer complicações para o tradutor. Porém, aqui também, as aparências enganam.

No que diz respeito à tradução dos nomes de pessoa, existem mais usos que regras. Os italianos, por exemplo, traduzem o nome de batismo de todo mundo e falam em Pietro Corneille e Onorato de Balzac; os espanhóis fazem a mesma coisa e falam em Juan La Fontaine, o que nos parece sumamente ridiculo. Entretanto, quando se tratava de figurantes imaginários, no Brasil também se costumava traduzi-1os. Assim fez Joāo Ribeiro, ao verter o Coração de de Amicis, mantendo em italiano apenas os sobrenomes. Modernamente, a tendência é deixar ambos intatos.

$\mathrm{Na}$ maioria das línguas, como em português também, existem formas carinhosas de nomes de pessoa, os chamados hipocorísticos. Robert chama-se familiarmente Bobby nos Estados Unidos, Giuseppe Beppe na Itália, Alexandr Sacha na União Soviética. O tradutor deve perceber quando numa obra uma personagem é designada por dois ou mais nomes; não deve equivocar-se sobre o sexo das personagens masculinas, cujo hipocorística termina em a, como Valia, Volodia e Duma (em vez de Valentin, Vladimir e Dmitri). Deve respeitar o uso russo de, nas falas respeitosas, se usar o nome da pessoa acompanhado do do pai: Ivan Ivanovitch. Deve ainda saber que em certas línguas a transcrição muda sensivelmente a forma dos nomes: em russo Heine torna-se Geine, Homero Gomero e Teókrito Feocrit. Não pode ignorar que os nomes da antiguidade greco-latina têm formas diferentes nas diversas línguas modernas: em italiano, por exemplo, Júpiter tem nome de Giove e Juvenal Giovenale.

Caso curioso é aquele em que os nomes próprios são empregados com valor de nomes comuns: os nossos Fulano, Sicrano e Beltrano em italiano transformam-se em Tizio, Gaio e Semprônio; em alemão eles ficam reduzidos a dois, Hinz e Kunz; em francês, a um só, M.Untel.

Além dos antopônimos, os topônimos, isto é, os nomes de lugar obrigam-nos também a redobrar de atençāo. Não devemos falar em Genève, Lyon e Marseille, pois temos em nossa língua as formas vernaculares Genebra, Liāo e Marselha, Pior ainda seria designar Firenze pelo nome francês de Florence, ou Bâle pelo nome alemāo de Basel.

Para maior confusão, existem as alterações impostas pela História, que transforma os nomes das cidades de acordo com seus possuidores sucessivos. Os nomes de Gdansk e Danzig, Wroslaw e Breslau, Kaliningrad e Königsberg referem-se à mesma cidade em épocas diferentes. Mas aqui já che- 
gamos ao substrato cultural especifico que o profissional deve adquirir de acordo com o campo em que trabalha.

$$
* * *
$$

Hả coisa mais fácil que uma sigla? Basta simplesmente copiá-la. Mas, devagar com o andor: as siglas são formadas pela reunião das letras iniciais dos vocábulos essenciais de uma denominação. Ora, esses vocábulos podem não ser os mesmos nas diversas línguas e mesmo que o sejam, podem estar em ordem diferente. Assim é que nós falamos em ONU (Organização das Nações Unidas) enquanto os norte-americanos e ingleses dizem UNO (United Nations Organization); e quando os russos se referem ao SSSR (Soiúz Soviétskikh Sotsialistitchéskikh Reppúblik) nós entendemos URSS.

Quer dizer então que devemos reconstituir a denominação de que a sigla constitui a abreviatura, traduzi-la e formar uma nova sigla com as iniciais de suas palavras em nossa língua. A regra nada tem de absoluto, pois certas siglas famosas ou famigeradas, como a GESTAPO alemã, a OVRA italiana, o KGB russo, a CIA norte-americana, nunca são traduzidas.

Eis um exemplo que mostra como o tradutor deve sempre manter-se a par da atualidade, ler os jornais com atenção e conformar-se à praxe que eles seguem.

Mas os numerais, ao menos devem estar isentos de problemas. Outro engano. No país da traduçāo, meio pode ser igual a um, e quatro a seis. Falando num homem de meio olho ou de meia perna, o húngaro refere-se a alguém que tenha um olho só, uma perna só. $O$ italiano diz C'erano quattro gatti, e para nós eram "meia dúzia de gatos pingados". Há muita diversidade quando se trata de quantidades indeterminadas: um menino que faz tudo que quer, na França faz suas 36.000 vontades (faire ses trente-six mille volontés). Em português há nítida preferência por sete: fala-se nos sete fôlegos do gato, no homem de sete instrumentos, em pintar o sete; o alemão usa também o mesmo numeral no mesmo sentido, mas noutras locuções: siebenmal klug para nós não será "sete vezes inteligente", mas "sabido", seine sieben Sachen zusammennehmen não será "juntar suas sete coisas", mas "pegar seus trens (e ir embora)". Como adivinhar que o nosso "são outros quinhentos" se diz em francês c'est une autre paire de manches. Acontece frequientemente que a locução figurada estrangeira em que entre algum numeral se traduz noutra lingua sem qualquer alusāo a números: se mettre sur son trente et un é, simplesmente, "endomingar-se". Como se vê, neste terreno também devemos ficar sempre de pé atrás. 
Enganar-se-ia, finalmente, quem julgasse que só se traduz linguagem, isto é, vocábulos. Há muitos outros elementos, além das palavras, que concorrem para o sentido de um texto: a ordem das palavras, o uso de maiusculas e minúsculas, a escolha das letras tipográficas, até a disposição de espaços em branco. E preciso conhecer as convençōes que regulam o uso desses ingredientes todos e que podem diferir de um idioma para outro.

Quanto à colocaçāo das palavras, sua ordem na frāse latina pode variar ao infinito, mas cada ordem diferente corresponde a outro matiz de pensamento. Enquanto isto, numa frase francesa a ordem das palavras geralmente é rígida, e portanto não influi no sentido do conjunto. Mas aqui há exceçōes, especialmente no caso dos adjetivos qualificativos que, antepostos ou pospostos ao substantivo, mudam de significado ou de conotação: lembremos un homme bon e un bonhomme, mon propre cahier e un cahier propre, un sacré farceur e un devoir sacré.

Em compensação, em alemão e inglês os adjetivos vêm regularmente antepostos, sendo pois a sua colocação questão de gramática, não de estilo. Coisa incrível, há tradutores nossos de inglês que não se perceberam ainda deste fato e em suas traduções usam "um inesquecivel dia", "uma incompreensivel frase", "um branco chapeu" e "um vermelho tomate". Nas línguas escandinavas, o artigo tem caráter definido ou indefinido segundo posposto ou anteposto ao substantivo. Em húngaro e em japonês, o sobreiome precede o nome; em italiano dá-se isto, mas apenas em documentos oficiais.

Veja-se ainda a diferença no uso das maiúsculas e das minúsculas. Nas linguas neolatinas, começar um substantivo com maiúscula é sinal de ênfase; em alemão é obrigação gramatical. Em inglês, é praxe escrever com maiúscula o pronome pessoal da primeira pessoa; nas outras línguas seria indício de megalomania.

No Brasil o travessão abre e fecha as falas das personagens, enquanto na Inglaterra esse papel é preenchido pelas aspas. Por sua vez, o travessão representa suspensão, espanto.

Em conclusão: todo elemento, mesmo nāo verbal, da página concorre para mensagem e por isso nāo deve ser negligenciado.

$$
\text { * * * }
$$

Chegamos ao fim de nossas considerações. Mesmo que por um milagre tivessem gravado tudo que acabam de ouvir, os meus prezados ouvintes possuiriam apenas algumas dicas, mas não saberiam traduzir. Traduzir aprende-se tra- 
duzindo. Os artesões de antigamente formavam-se como aprendizes ao lado de um mestre, com quem passavam longos anos. É muito difícil encontrar um mestre tradutor que aceite aprendizes. Os cursos de tradução ensinam os conhecimentos básicos indispensáveis ao métier, mas o modo de fazer é objeto de aprendizado individual. Cada tradutor deve ser seu próprio mestre. Ele mesmo deve inventar seus exercicios, confrontar um original com alguma tradução impressa, comparar a sua própria tradução com uma dessas versōes, justapor duas ou mais versões do mesmo texto, organizar sua relação de falsos-amigos, de expressōes idiomáticas, de equivalentes sintáticos. E preciso resignar-se à gratuidade desses exercicios antes de se atrever a fazer traduçōes remuneradas. O lema horaciano - Multa tulit fecitque puer, sudavit et alsit ("muito fazer e suportar em jovem, suar e tremelicar") aplica-se ao tradutor como a ninguém.

Naturalmente existem também livros especialmente dedicados à tradução, tanto mais úteis quanto maior o número de casos concretos que registram. Peço licença para, como despedida, indicar-lhes um livrinho meu, A Tradução Vivida em edição da Nova Fronteira. Se gostaram da palestra de hoje, ele há de diverti-los. 